\title{
Sonoelastography in the evaluation of capsule formation after breast augmentation - preliminary results from a follow-up study
}

\author{
Katarzyna Paczkowska ${ }^{1}$, Paweł Rzymski ${ }^{1}$, Mikołaj Kubasik ${ }^{2}$, Tomasz Opala ${ }^{1}$
}

\begin{abstract}
${ }^{1}$ Department of Mother's and Child's Health, Poznan University of Medical Sciences, Gynecologic and Obstetrical University Hospital, Poznan, Poland 2Individual Plastic Surgery Practice, Poznan-Zakrzewo, Poland
\end{abstract}

Submitted: 19 November 2014

Accepted: 28 November 2014

Arch Med Sci 2016; 12, 4: 793-798

DOI: 10.5114/aoms.2015.49935

Copyright @ 2015 Termedia \& Banach

\begin{abstract}
Introduction: There are many indications for breast augmentation, including reconstruction after mastectomy, correction of congenital disorders and cosmetic procedures. The most frequent local complication of this surgery is capsule formation due to fibrosis. The aim of the study was to assess the usefulness of sonoelastography in the evaluation of capsule formation around silicone implants.

Material and methods: The study group included 13 patients aged 20 to 41 , who underwent breast augmentation with silicone implants. Their 26 breasts were examined before surgery, 7 and 14 days and a minimum of 8.5 months after surgery. The breast stiffness was assessed with tonometry and shear wave elastography to evaluate elasticity of the breast tissue and capsule formation after surgery.

Results: We assessed the correlation between capsular elasticity measured at successive visits and the Baker scale. There were no significant relationships between any pairs of variables $(p>0.05)$. We also analyzed the correlation between the time of the follow-up and changes in the tissue elasticity of every region - no significant relationship was found. The greatest decrease in pericapsular elasticity was established in lower and inner quadrants. Moreover, there was a significant difference between the elasticity of the tissue before and 1 week after surgery $(p<0.05)$ and no significant changes in the elasticity before surgery and at the end of the follow-up.

Conclusions: Sonoelastography is precise in evaluation of capsule formation after breast augmentation. It may show changes that cannot be assessed using palpation.
\end{abstract}

Key words: capsular contracture, silicone implants, shear wave elastography.

\section{Introduction}

Breast augmentation is a surgical procedure in which silicone implants have been used for more than 50 years instead of previous used materials [1]. There are many indications for this procedure, including reconstruction after mastectomy, correction of congenital disorders and cosmetic procedures, performed to improve self-acceptance of the body [2].

Complications of breast augmentation consist of local and systemic side effects. In the literature, there are case reports about the occurrence

\author{
Corresponding author: \\ Assoc. Prof. Pawel Rzymski \\ MD, PhD \\ Department of Mother's \\ and Child's Health \\ Poznan University \\ of Medical Sciences \\ Gynecologic and Obstetrical \\ University Hospital \\ 33 Polna St \\ 60-535 Poznan, Poland \\ Phone: +48 605393096 \\ Fax: +48618419618 \\ E-mail: \\ parzymsk@gpsk.am.poznan.pl
}


of systemic connective tissue diseases after implant insertion, but such severe side effects are uncommon [3]. Moreover, meta-analyses of occurrence of severe systemic complications caused by presence of silicone implants in the human body have not confirmed or refuted the procedure's safety $[4,5]$.

Local side effects are more common than systemic ones, and the most frequent one is capsule formation. The largest cell population detected in the fibrous capsule comprises macrophages and fibroblasts, and they form around the implant a frontier layer. Beneath this layer, activated CD4+ lymphocytes were found, but B cells were not detected, which means that silicone induces an immune system response via T cells. Also involved in capsule formation are heat shock protein 60 expression and the appearance of extracellular matrix proteins and adhesion molecules [6].

On the other hand, it is worth noting that fibrosis is a physiological, local inflammatory tissue reaction to a foreign body, and there is no possibility to avoid it. During the years of development and improvement of the surgical technique by the use of various materials and a change of implant placement, there has not been found a perfect surgical protocol that completely eliminates side effects.

Sonoelastography is an examination in which the stiffness of the tissue is described by elastic moduli. There are two types of elastographic examination: conventional and shear wave elastography. In the first one, compression of the tissue is required, and the result of the examination is the color-coded map of tissue elasticity. In the shear wave method, tissue compression is replaced by mechanical vibration produced by an ultrasonic probe $[7,8]$.

The aim of our study was to assess the usefulness of sonoelastography in the evaluation of capsule formation after breast augmentation.

\section{Material and methods}

The study group included 13 healthy patients aged 20 to 41 (mean age: $32.8 \pm 3.8$ ) years, in habitants of Poznan region with body mass index (BMI) $21.6 \pm 1.3 \mathrm{~kg} / \mathrm{m}^{2}$. Patients were recruited from a population of 200 consecutively performed breast augmentations by one coauthor. The calculation of the representative probe was planned to achieve statistical significance of $p<0.05$. Patients enrolled in the study were volunteers who before routine plastic surgery agreed to attend additional examinations without changing the medical treatment. The exclusion criteria were besides exclusion for surgery: changes in hormonal treatment or contraceptives at least 6 months before, planned change in this treatment in the next 12 months, modification of physical activity 3 months before surgery, pregnancy, C-reactive protein above $5 \mathrm{mg} / \mathrm{dl}$, chronic hepatic, renal, nervous, cardiac disease. They underwent breast augmentation surgery with silicone-filled texturized implants (Allergan, USA). The procedure was performed by a senior plastic surgeon between September 2010 and March 2011. The dual-plane surgical technique was used, as described previously $[9,10]$.

All 26 breasts were assessed carefully before surgery (first examination) and at the control visits. The second visit was 7 days after the intervention, the third one 14 days after, and the last one (fourth examination) about 1 year after the intervention. The time of follow-up ranged from 8.5 to 21 months; the mean was 14.4 months. The examination by tonometry and palpation performed by the surgeon was blinded for ultrasonographic and elastographic evaluation performed by the sonographer (and vice versa).

The visit included palpation and imaging techniques check-up - ultrasound examination and real-time shear wave sonoelastography (Aixplorer, France). This method involves measurement of the tissue stiffness (Young's moduli) presented as a color-coded image in tissue layers: glandular, fatty, muscular and pericapsular. The measurements included the examination of the four quadrants. In the inner and upper ones it was possible to determine the value of the fat, glandular, muscle tissue and fascia elasticity. In the lower and outer quadrants only the value of the fat and glandular tissue was assessed. Additionally we measured minimum and maximum thickness $(\mathrm{mm})$ of the capsule using the harmonic imaging option $(\mathrm{HI})$ in each quadrant at the fourth visit.

The breast stiffness was also determined by applanation tonometry, and the value of the intramammary pressure was calculated from the formula $P=F / A$, where $F$ is the force applied to the organ and $A$ is the contact area of the disc, which weighed $213 \mathrm{~g}$ and had a diameter of $20.3 \mathrm{~cm}[9,10]$.

After surgery, the outcome and the capsular contracture were established by a physician's examination and evaluated using a modified Baker scale $(1 ; 1.5 ; 2 ; 2.5 ; 3 ; 4)[11]$.

\section{Statistical analysis}

All data were collected and then analyzed using the program Sigma Plot version 11.0. Spearman's test was used to evaluate correlations. One-way repeated measures ANOVA and the Holm-Sidak test were used to evaluate changes in parameters during follow-up. A $p$ value $<0.05$ was assumed significant. The study was approved by the local bioethics committee. 


\section{Results}

We evaluated the correlation between capsular elasticity measured at successive visits and the Baker scale. The Spearman test was used and the results are shown in Table I. There were no significant relationships between any pairs of variables $(p>0.05)$, but a borderline correlation was noted between inner quadrants' pericapsular elasticity and Baker score.

We also analyzed the correlation between time of follow-up specified in months and changes in tissue elasticity in every region. The Pearson correlation test was performed. Change in tissue elasticity was defined as the difference between measurements at the second and fourth visit. No significant correlation was found. Results are shown in Table II.

The capsular elasticity was measured during each visit; we analyzed it and compared the results using one-way repeated measures ANOVA. Means with standard deviations are presented in Table III. In all quadrants there was a significant difference $(p<0.05)$ among groups. We also performed the Holm-Sidak test to identify differences between measurements. Results are shown in Table III. What is important, in all quadrants there was a significant difference $(p<0.05)$ in capsular elasticity between the measurements at the

Table I. Correlation between capsular elasticity and Baker scale

\begin{tabular}{|lccc|}
\hline Area & $\begin{array}{c}\text { Correlation of capsular } \\
\text { elasticity, measured at second } \\
\text { visit*, with Baker scale }\end{array}$ & $\begin{array}{c}\text { Correlation of capsular } \\
\text { elasticity, measured at third } \\
\text { visit**, with Baker scale }\end{array}$ & $\begin{array}{c}\text { Correlation of capsular } \\
\text { elasticity, measured at fourth } \\
\text { visit***, with Baker scale }\end{array}$ \\
\hline Upper quadrants & $R=0.089 ; p=0.66$ & $R=0.02 ; p=0.94$ & $R=-0.18 ; p=0.37$ \\
\hline Outer quadrants & $R=-0.21 ; p=0.30$ & $R=0.22 ; p=0.28$ & $R=-0.34 ; p=0.086$ \\
\hline Lower quadrants & $R=0.063 ; p=0.76$ & $R=0.12 ; p=0.55$ & $R=0.065 ; p=0.75$ \\
\hline Inner quadrants & $R=-0.1 ; p=0.62$ & $R=0.31 ; p=0.12$ & $R=0.38 ; p=0.058$ \\
\hline
\end{tabular}

${ }^{*}$ Second visit means after surgery, ${ }^{* *}$ third visit 14 days after surgery, ${ }^{* * *}$ fourth visit means the end of follow-up.

Table II. Correlation between change in tissue elasticity and time of follow-up

\begin{tabular}{|lcccc|}
\hline Tissue & $\begin{array}{c}\text { Correlation between } \\
\text { change* in tissue } \\
\text { elasticity and } \\
\text { follow-up** in upper } \\
\text { quadrants }\end{array}$ & $\begin{array}{c}\text { Correlation between } \\
\text { change* in tissue } \\
\text { elasticity and } \\
\text { follow-up** in outer } \\
\text { quadrants }\end{array}$ & $\begin{array}{c}\text { Correlation between } \\
\text { change* in tissue } \\
\text { elasticity and } \\
\text { follow-up** in lower } \\
\text { quadrants }\end{array}$ & $\begin{array}{c}\text { Correlation between } \\
\text { change* in tissue } \\
\text { elasticity and } \\
\text { follow-up** in inner } \\
\text { quadrants }\end{array}$ \\
\hline Glandular & $R=-0.21 ; p=0.31$ & $R=0.06 ; p=0.75$ & $R=0.27 ; p=0.19$ & $R=-0.25 ; p=0.23$ \\
\hline Fatty & $R=-0.15 ; p=0.46$ & $R=-0.06 ; p=0.77$ & $R=-0.28 ; p=0.17$ & $R=-0.12 ; p=0.56$ \\
\hline Fascia & $R=-0.1 ; p=0.64$ & - & - & $R=-0.23 ; p=0.26$ \\
\hline Muscular & $R=0.07 ; p=0.76$ & $R=0.07 ; p=0.73$ & $R=0.02 ; p=0.93$ & $R=-0.18 ; p=0.38$ \\
\hline Pericapsular & $R=0.01 ; p=0.97$ & $R=0.17 ; p=0.42$ \\
\hline
\end{tabular}

*Change in tissue elasticity was defined as the difference between measurements at second and fourth visit; ${ }^{* \star}$ follow-up was specified as the observation time in months.

Table III. Means of capsular elasticity

\begin{tabular}{|lcccc|}
\hline Visit & $\begin{array}{c}\text { Mean of capsular } \\
\text { elasticity in upper } \\
\text { quadrants }\end{array}$ & $\begin{array}{c}\text { Mean of capsular } \\
\text { elasticity in outer } \\
\text { quadrants }\end{array}$ & $\begin{array}{c}\text { Mean of capsular } \\
\text { elasticity in lower } \\
\text { quadrants }\end{array}$ & $\begin{array}{c}\text { Mean of capsular } \\
\text { elasticity in inner } \\
\text { quadrants }\end{array}$ \\
\hline II & $19.6 \pm 4.52$ & $24.73 \pm 7.77$ & $22.72 \pm 6.64$ & $25.02 \pm 7.4$ \\
\hline III & $18.55 \pm 6.22$ & $21.61 \pm 6.07$ & $23.59 \pm 7.53$ & $18.02 \pm 3.98$ \\
\hline IV & $14.95 \pm 5.18$ & $19.53 \pm 4.5$ & $15.69 \pm 4.45$ & $t=0.787 ; p=0.435$ \\
\hline Holm-Sidak test: & & & & 23.93 \\
\hline II vs. III & $t=3.591 ; p<0.001$ & $t=2.061 ; p=0.045$ & $t=0.588 ; p=0.559$ & $t=4.289 ; p<0.001$ \\
\hline III vs. IV & $t=2.784 ; p=0.008$ & $t=1.376 ; p=0.175$ & $t=5.395 ; p<0.001$ & $t=5.076 ; p<0.001$ \\
\hline II vs. IV & $t=0.807 ; p=0.423$ & $t=3.437 ; p=0.001$ & $t=4.807 ; p<0.001$ & $t=01$ \\
\hline
\end{tabular}


Table IV. Analysis of different tissues before surgery and at second and fourth visit

\begin{tabular}{|lcccc|}
\hline $\begin{array}{l}\text { Analyzed pairs of } \\
\text { measurements }\end{array}$ & Glandular tissue & Fatty tissue & Muscular tissue & Fascia \\
\hline I vs. II & $p<0.002$ & $p<0.001$ & $p=0.001$ & $p=0.003$ \\
\hline I vs. IV & $p=0.618$ & $p=0.935$ & $p=0.155$ & $p=0.517$ \\
\hline
\end{tabular}

Table V. Correlations between elastographic stiffness and ultrasound evaluation of the capsule

\begin{tabular}{|lcc|}
\hline Capsule elasticity & $\begin{array}{c}\text { Minimum capsule thickness } \\
\text { (harmonic imaging) }\end{array}$ & $\begin{array}{c}\text { Maximum capsule thickness } \\
\text { (harmonic imaging) }\end{array}$ \\
\hline In upper quadrants & $R s=0.10 ; p=0.62$ & $R s=0.17 ; p=0.39$ \\
\hline In outer quadrants & $R s=0.15 ; p=0.47$ & $R s=0.20, p=0.33$ \\
\hline In lower quadrants & $R s=0.10 ; p=0.60$ & $R s=0.13 ; p=0.51$ \\
\hline In inner quadrants & $R s=0.37 ; p=0.07$ & $R s=0.20 ; p=0.30$ \\
\hline
\end{tabular}

second and fourth visit. The greatest decrease in pericapsular elasticity was in lower and inner quadrants.

The results in Table IV suggest that quick expansion of tissues after implant insertion caused the increase in tissue elasticity. The return to values similar to preoperative after follow-up indicates possible adaptation of the tissues.

Because we did not observe more advanced capsule formation (Baker grades 3 and 4), direct detection analysis was not possible and should be planned for longer follow-up. Thus we analyzed the correlations between pericapsular stiffness and ultrasound thickness of the capsule. The results are presented in Table V. Tonometry did not correlate either with pericapsular stiffness or with the thickness of the capsule measured with ultrasonography.

\section{Discussion}

Capsule formation is the most common complication that occurs in the place of the connections between the tissue and silicone implants [12]. The incidence of this side effect ranges from $0.5 \%$ to $30 \%$ depending on the research $[13,14]$. In our study, we did not observe this side effect (the highest value of the Baker score was 2.5), but it may require a larger study group or longer follow-up.

In different studies the occurrence of pericapsular fibrosis was variable due to different factors such as the type of implant, implant duration or implant position. Peters et al. suggested in their study that submuscular implant insertion, in comparison to subglandular position, significantly reduces the risk of capsule formation [15]. Studies have also shown that textured silicone implants reduce the frequency of capsular contracture [16, 17]. In our study the risk of capsule formation was reduced by using the same type of implants (tex- turized) and surgical procedure (submuscular) in all patients.

The Baker scale was created to evaluate capsular contraction, but this classification could be somewhat subjective. In the Baker scale capsule formation gives a result of 3 or 4 [18]. In our study the highest score was 2.5 , and it was determined in two breasts, in two different patients. The evaluation of the second breast of these patients was correct, and the result on the Baker scale was lower. The subjective assessment is a reason why other methods of evaluation were introduced to enable objectification of the examination, especially imaging techniques, such as ultrasound examination, computed tomography (CT) and magnetic resonance imaging (MRI) [19].

Sonoelastography is a non-invasive examination which may be used in the assessment of capsule formation. It is important to note that this method give us a possibility to examine all tissue elasticity separately, which is impossible in palpation and the Baker score evaluation. On the other hand, the results of the research showed that there is no correlation between the elastographic measurement at the second and third visit (postoperatively) and the Baker score. Prantl et al. observed a high correlation between these evaluations [20]. Differences in the results might be caused by a more variable group in the Prantl study (in our study, the score on the Baker scale was not higher than 2.5) or insufficiently large groups: in Prantl's study the research group included 11 patients, in ours 13 patients. Our results and those of Prantl are the first results so far in evaluation of capsule formation by the new method. In other applications sonoelastography was proved to be reproducible and useful in breast tumor detection [21, 22].

What is more, we found a decrease in capsular elasticity in four quadrants, which may suggest 
a decrease of the inflammation around the implants, adaptation and remodeling of the tissue. The study also revealed a significant difference in all tissue elasticity if we compare the results before and 1 week after the surgery. The value of tissue elasticity at the end of the follow-up had become similar to the one from the examination before insertion of implants $(p>0.05)$. This result led us to hypothesize about tissue adaptation, but this aspect requires further evaluation.

Moreover, there was no correlation between change in tissue elasticity, defined as the difference between measurements at the second and fourth visit, and time of follow-up. This result led to the hypothesis that after a few months there are no significant adaptive changes in tissue that has been damaged by mechanical stimuli.

The research we have presented is a pilot study and it needs to be confirmed in the future in a larger group of patients. There are several limitations of this study. The patients were volunteers from a population of breast augmentation surgery patients, and we cannot exclude we cannot exclude some environmental, hormonal or physical activity confounding factors in our population. Capsule formation starts after surgery, but could occur in a longer time (years), and we cannot exclude long-lasting complications. Thus we plan to observe patients up to 10 years, but the pioneer results from a shorter follow-up could lead other researchers to design more studies. As we did not observe more advanced capsule formation, the evaluation of sonoelastography as a detection tool compared to gold standard ultrasound was not possible. However, we previously described the power of detecting capsule formation in advanced cases [10]. That is why we estimated no correlations between these methods, which represent two different physical features of tissues: stiffness and ultrasonic rebound to measure its thickness. We can only speculate that further research concerning the stiffness to thickness ratio could tell us more about the tissue physical density and probably capsular severity in the future.

In conclusion, capsular elasticity measured by sonoelastography decreases over the follow-up period. Other breast tissues increase their stiffness measured by sonoelastography before and shortly after surgery, but their elasticity returns to primary values over the follow-up period. We did not prove a correlation between Baker score and elasticity measured by sonoelastography in this pilot study.

\section{Conflict of interest}

The authors declare no conflict of interest.

\section{References}

1. Miller TA. Silicone and plastic surgery. Plast Reconstr Surg 1997; 100: 1307-8.

2. Beale S, Hambert G, Lisper H, Ohlsen L, Palm B. Augmentation mammoplasty: the surgical and psychological effects of the operation and prediction of the result. Ann Plast Surg 1984; 13: 279-97.

3. Appleton BE, Lee P. The development of systemic sclerosis following augmentation mammoplasty. J Rheumatol 1993; 20: 1052-4.

4. Karlson EW, Hankinson SE, Liang MH, et al. Association of silicone breast implants with immunologic abnormalities: a prospective study. Am J Med 1999; 106: 11-9.

5. Tugwell P, Wells G, Peterson J, et al. Do silicone breast implants cause rheumatologic disorders? A systemic review for a court-appointed national science panel. Arthritis Rheum 2001; 44: 2477-84.

6. Wolfram D, Rainer C, Niederegger H, Piza H, Wick G. Cellular and molecular composition of fibrous capsules formed around silicone breast implants with special focus on local immune reactions. J Autoimmun 2004; 23: 81-91.

7. Rzymski P, Wysocki PJ, Kycler W, Opala T. Correlation between insulin resistance and breast elasticity heterogeneity measured by shear wave elastography in premenopausal women - a pilot study. Arch Med Sci 2011; 7: 1017-22.

8. Rzymski P, Skórzewska A, Skibińska-Zielińska M, Opala T. Factors influencing breast elasticity measured by the ultrasound shear wave elastography - preliminary results. Arch Med Sci 2011; 7: 127-33.

9. Rzymski P, Kubasik M, Gaca M, Opala T. Is the shear wave sonographic elastography correlated with pain after breast augmentation with silicone implants an indication of inflammatory activity? A preliminary report. Videosurgery Miniinv 2011; 6: 217-25.

10. Rzymski P, Kubasik M, Opala T. Use of shear wave sonoelastography in capsular contracture before and after secondary surgery: report of two cases. J Plast Reconstr Aesthet Surg 2011; 64: 309-12.

11. Reid RR, Greve SD, Casas LA. The effect of zafirlukast (Accolate) on early capsular contracture in the primary augmentation patient: a pilot study. Aesthet Surg J 2005; 25: 26-30.

12. Embrey M, Adams EE, Cunningham B, Peters W, Young VL, Carlo GL. A review of the literature on the etiology of capsular contracture and a pilot study to determine the outcome of capsular contracture interventions. Aesth Plast Surg 1999; 23: 197-203.

13. Araco A, Gravante G, Araco F, et al. Capsular contracture: results of 3002 patients with aesthetic breast augmentation. Plast Reconstr Surg 2006; 118: 1499-500.

14. Eisenmann-Klein M. Breast implants: the past, the presence, the future. Eur Plast Surg Rev 1999; 3: 33-43.

15. Peters WJ, Smith D, Fornasier VL, Lugowski S, Ibanez D. An outcome analysis of 100 women after explantation of silicone gel breast implants. Ann Plast Surg 1997; 39: 9-19.

16. Duffy MJ, Woods JE. Healthy risks of failed silicone gel breast implants: a 30-year clinical experience. Plast Reconstr Surg 1994; 94: 295-9.

17. Copeland M, Choi M, Bleiweiss IJ. Silicone breakdown and capsular synovial metaplasia in textured-wall saline breast prosthesis. Plast Reconstr Surg 1994; 94: 628-33.

18. Siggelkow W, Klosterhalfen B, Klinge U, Rath W, Faridi A. Analysis of local complications following explantation of silicone breast implants. Breast 2004; 13: 122-8. 
19. Morgan DE, Kenney PJ, Meeks MC, Pile NS. MR imaging of breast implants and their complications. Am J Radiol 1996; 167: 1271-5.

20. Prantl L, Englbrecht MA, Schoeneich M, Kuehlmann B, Jung EM, Kubale R. Semiqauantitative measurements of capsular contracture with elastography - first results in correlation to Baker Score. Clin Hemorheol Microcirc 2014; 58: 521-8.

21. Berg WA, Corgrove DO, Dore CJ, et al. Shear-wave elastography improves the specificity of breast US: the BE1 multinational study of 939 masses. Radiology 2012; 262: 435-49.

22. Rzymski P, Wilczak M, Opala T. Breast elastography new diagnostic quality or technologic buble. Pos Hig Med Dośw 2014; 68: 1180-4. 